\title{
Entre a Vontade e a Necessidade: Negociação Sexual em Tempos de AIDS*
}

\author{
REGINA MARIA BARBOSA, \\ WILZA VIEIRA VILLELA \\ ANNA PAULA UZIEL **
}

A crescente progressão da AIDS entre a população feminina no Brasil, no final da década de 80, veio agravar a situação, já bastante precária, da saúde, particularmente quanto a aspectos relacionados ao exercício da sexualidade e da reprodução. Em um quadro relativamente caótico e contraditório, o aumento do uso de contraceptivos, e a conseqüente queda nas taxas de fecundidade, convive com o recurso indiscriminado à esterilização e ao parto cesáreo, com a expansão da prática clandestina do aborto e com elevados índices de mortalidade materna.

A contradição entre as conquistas femininas e sua absorção pelo tecido social não se restringe, entretanto, apenas ao campo da saúde. Ao mesmo tempo em que a sexualidade e o direito à contracepção se tornam objetos de debates públicos, observa-se também o aumento da escolarização e do emprego feminino, sem um correlativo aumento no nível de riqueza dessa população.

Da mesma forma, enquanto o discurso de "igualdade entre os sexos" extrapola as camadas mais intelectualizadas para ganhar hegemonia nos centros

* O presente artigo bussca suscitar atgumas questōes sobre negociação sexual, gênero e poder, que vêm sendo aprofundadas $\mathrm{cm}$ uma linha de pesquisa en andamento no Programa de Estudos e Pesquisa em Gênero, Sexualidade e Saúde, descnvolvido no Instituto de Medicina Social/UERJ.

*: Regina Maria Barbosa é pesquisadora do Instituto de Saúde de São Paulo, doutoranda do Instituto de Medicina Social da UERJ. Wilza Vieira Vilela é médica, psiquiatra, pesquisadora do Instituto de Saúde de São Paulo. Anna Paula Uziel é psicóloga, mestranda em Psicologia Clínica na PUC-RJ e pesquisadora do Instituto de Medicina Social da UERJ. 
urbanos, aumentam os casos de violência contra mulheres e cresce o número de famílias cuja chefia é exclusivamente feminina. Assim, o que se configura para as mulheres brasileiras nos anos 90 é uma situação ainda mais complexa e contraditória, que manterá esse segmento populacional em uma situação de extrema vulnerabilidade.

No que diz respeito à epidemia de AIDS, estimava-se que existissem, em 1994, no Brasil, aproximadamente, 500 mil pessoas com mais de 15 anos infectadas, sendo 73 mil mulheres, ou seja, uma mulher infectada para cada 667 habitantes do sexo feminino. ${ }^{1}$

Além disso, os dados disponíveis a respeito do perfil da epidemia indicam que é basicamente através das relaçōes sexuais que a população feminina - de modo geral constituída por mulheres jovens, en tre 20 e 39 anos, na sua maioria donas de casa ou empregadas domésticas - está se infectando. Nesse sentido, focalizar a atenção nas estratégias de prevenção voltadas para a diminuição da transmissão sexual do HIV é atualmente uma questão central para o controle da epidemia.

Dentre essas estratégias, tem sido enfatizada a necessidade de ampliação das opções de proteção, no sentido do desenvolvimento de métodos e dispositivos de prevenção sob o controle feminino e que, ao mesmo tempo, previnam de maneira eficaz a gravidez indesejada e as doenças sexualmente transmissíveis/AIDS. ${ }^{2}$ Deste ponto de vista, idealmente, tais métodos não deveriam depender de qualquer negociação de seu uso com os parceiros sexuais e teriam de ser confortáveis, de fácil acesso, baixo custo e seguros para a saúde. Entretanto, nada que atenda a todos esses atributos parece ser possível a curto e médio prazos. O condom feminino e os microbicidas-virucidas, as únicas possibilidades que se colocam como perspectivas concretas em um futuro próximo, embora ampliem as opções femininas de proteção, não descartam a necessidade de negociação para o seu uso, já que exigem pelo menos a concordância do parceiro.

Assim sendo, dada a impossibilidade de um método que possa ser usado sem o conhecimento do parceiro - como foi possível com os métodos contraceptivos, no caso da contracepção hormonal e da esterilização -, a busca de estratégias que visem aumentar a capacidade da mulher negociar o uso de métodos de proteção disponíveis tem sido cada vez mais enfatizada para

1. R. Barbosa, Saúde Reprodutiva e AIDS: Novas e Velhas Questỏes, Rio de Janeiro, Instituto de Medicina Socia//UERJ, 1995 (aguardando publicaçăa).

2. Z. A. Stein, "HIV Prevention: The Need for Methods Women Can Use", American Journal of Public Health, vol. 80, n4. 1990. 
diminuir a vulnerabilidade da população feminina à infecção pelo HIV e outras DSTs.

A necessidade de ampliar a capacidade de proteção feminina em relação às conseqüências indesejáveis da atividade sexual — sendo a gravidez apenas uma delas - é, sem dúvida, uma importante dimensão do problema que a epidemia de AIDS trouxe à tona. Pensar a atividade sexual dentro de um contexto de proteção à saúde, e não mais de reprodução é, na verdade, uma mudança fundamental na perspectiva com que as questões relacionadas à sexualidade foram tratadas até então. ${ }^{3}$

Na realidade, a AIDS explicita o que as organizaçōes que lutam pelos direitos reprodutivos, e em particular as feministas, têm denunciado há décadas no terreno da reprodução humana: soluções técnicas, embora necessárias, não bastam por si só para enfrentar situações complexas como esta. É necessário, entre outras coisas, estudar e compreender os fatores e as diversas dimensões que mantêm os indivíduos, especialmente as mulheres, em situações de desigualdade/desvantagem, no plano individual e social, e interferem no processo de tomada de decisões direcionado à proteção de sua saúde e de sua integridade física.

Dentre as diferentes possibilidades estratégicas de enfrentamento da siłuação desvantajosa da mulher, tem merecido destaque o aprofundamento da compreensão dos cenários objetivos e subjetivos que transformam "machos" e "fêmeas" em homens e mulheres. A perspectiva é que essa transformação e a relação que se estabelece entre homens e mulheres não é derivada das peculiaridades anátomo-fisilógicas de cada um, e sim da maneira como cada sociedade lhes atribui significado e valor.

Assim, as características distintas entre homens e mulheres, no plano comportamental ou da construção da subjetividade, não seriam uma continuidade ou uma consequiência natural das suas peculiaridades no plano biológico, devendo ser tomadas como construções sociais.

Segundo Costa, ${ }^{4}$ é apenas a partir do século XVIII que a distinção e a desigualdade entre mulheres e homens passam a ter como pressupostos a diferença biológica entre os sexos. Até então, do ponto de vista anátomo-fisiológico, existia apenas um sexo, o masculino, e a mulher era seu representante inferior. A necessidade de explicar a diferença entre mulheres e homens à partir

3. WHO/GPA, Sexual Negotiation, the Empowerment of Women and the Female Condom, 1993, mimeo.

4. J. F. Costa, A Face e o Verso. Estudos sobre o Homoerotismo 2, tese apresentada ao concurso para professor titular do Instituto de Medicina Social/UERJ, Rio de Janeiro, maio de I995. 
do dimorfismo sexual opera-se na medida em que os ideais igualitários da revolução burguesa necessitavam de uma justificativa de ordem natural para a desigualdade entre homens e mulheres. Pensadores e pesquisadores da época emperharam-se, então, em descobrir elementos diferenciadores, e localizaram no sexo a desigualdade da mulher: a bissexualização do prazer sexual, da constituição nervosa e da constituição óssea tornam mais "consistente" a inferioridade. Dessa forma, assiste-se, nas ciências humanas e sociais, ancoradas no conhecimento biomédico, a constituiçãa de uma inversão: as desigualdades sociais entre homens e mulheres que até então informavam a diferença sexual (no sentido anátomo-fisiológico) passam a ser explicadas por ela e, assim, o sexo determina o gênero.

A noçăo de gênero, elaborada primeiramente pelas feministas americanas nos anos 70 e 80 , surge exatamente para afirmar o caráter fundamentalmente social das diferenças baseadas no sexo e rejeitar o determinismo biológico que justificava, desde aquele momento, tais diferenças.

Ao longo das duas últimas décadas a categoria gênero tem sido usada de diferentes maneiras, existindo um debate acirrado, entre as teóricas feministas, a respeito do estatuto analítico ou empírico desse conceito. ${ }^{5}$ Este debate não está de modo algum encerrado; pelo contrário, cada vez mais sua utilização como recurso de análise tem se mostrado útil para o aprofundamento da reflexão sobre as relações entre homens e mulheres.

Outro aspecto que tem suscitado intensa discussão é a natureza específica das relações circunscritas pelo conceito. Consoante com sua vocação política original, a teoria feminista tem freqüentemente tomado o conceito de gênero da perspectiva do poder, considerado como constitutivo da relação entre homens e mulheres na sociedade e, consequientemente, intrínseco à configuração dos gêneros. ${ }^{6}$

Sob esse enfoque, torna-se fundamental reconhecer os caminhos pelos quais o poder opera na relação de gênero, suas múltiplas dimensões e contornos e quais são as fontes que alimentam e mantêm a desigualdade entre homens e mulheres. Segundo Foucault, ${ }^{7}$ trata-se de investigar como se dá o processo de sujeição dos corpos, não se tomando o poder como fenômeno homogêneo de

5. J. Scott, Gender and the Politics of History, Nova Iorque, Columbia University Press, 1988; S. Koffes, "Categoria Analítica c Empírica, Gênero e Mulher: Disjunçōes, Conjunçōes e Mediaçōos", Cadernos Pagu, $\mathrm{n}^{\circ}$ 1, IFCH/Unicamp, 1993; M. L. Heilborn, "De que Gênero Estamos Falando", Sexualidade, Gênero e Sociedude, ano 1, 10 2, 1994.

6. G. Rubin, "The Traffic in Woment Notes on the "Political Economy of Sex", in R. Rapp, od, Towards an Anthropology of Women, Nova Iorque. Monthly Review Books, 1975; J. Scot, Gender and the.... op. cit.

7. M. Foucault, Microfísica do Poder, Rio de Janeiro, Graal, 1979. 
dominação, mas a partir da compreensão de que o poder $€$ algo que circula, funciona em rede. Assim, os indivíduos estão sempre na posição de exercer poder e sofrer sua ação, são "centros de transmissão", sendo o indivíduo um dos efeitos do poder.

A apropriação do poder se dá por diversas instâncias, não há pólos fixos. No campo das relações entre homens e mulheres o conhecimento, em especial o médico, a autoridade legal e religiosa, as ideologias do machismo e da passividade feminina, por exemplo, são algumas das fontes - cujo acesso é em geral dominado pelos homens - que têm contribuído para manter a assimetria das relaçōes de gênero em uma dimensão praticamente universal. ${ }^{8}$

Por outro lado, homens e mulheres em diferentes culturas possuem variados papéis e status sociais, moldados não apenas pelo gênero, mas também pela idade, raça e classe social. Da mesma forma, essa modelagem se dá no campo da sexualidade, originando a possibilidade de múltiplas experiências e múltiplos sistemas de significados sexuais, cuja compreensão e análise, segundo Parker ${ }^{9}$ é particularmente importante para entender as características da vida sexual brasileira, marcada pela idéia de um povo singularmente sexual em uma terra exótica ${ }^{10}$ e fortemente patriarcal. Desde o Brasil colônia as proibições reforçam as divisões de gênero, traçando perfis cotidianos e para "a vida eterna". Masculinidade e feminilidade são definidas por oposição e têm a violência como "divisor de águas". Em meio aos diversos mitos que compõem a subjetividade brasileira, a mulher é sempre inferior, objeto de dominação, ainda que "bela e desejada".

Nesse sentido, Parker ressalta que, tal como o mundo social, o universo sexual está dividido, segmentado e recortado por várias éticas, por múltiplos sistemas de significados sexuais, distintos, porém complementares e, muitas vezes, opostos e contraditórios, mas que, de alguma maneira, conseguem se entrelaçar e interpenetrar na tessitura da vida social. Entretanto, enfatiza que a forma e os meios pelos quais os indivíduos encaram esse complexo sistema de significados sexuais não são absolutamente aleatórios, sendo eles mesmos estruturados não só pelo sistema em si, como também por condicionantes mais amplos resultantes da organização da sociedade brasileira. Assim, uma mulher,

8. C. S. Vance, "Pleasure and Danger: Toward a Politics of Sexuality", in C. S. Vance, ed., Pleasure and Danger: Exploring Female Sexuality, Boston, Routledge and Kegan Paul, 1984.

9. R. G. Parker, Corpos, Prazeres e Paixöes. A Cultura Sexual no Brasil Contemporâneo, São Paulo, Editora Best Seller, 1991.

10. O. Souza, Fantasia de Brasil. As Identificaçöes na Busca da Identidade Nacional, Tese de Doutorado, 1993; C. Calligaris, Hello Brasil! Noras de um Psicanalista Europeu Viajando pelo Brasil, Sāo Paulo, Escuta, 1992. 
independentemente de classe, religião ou raça, terá à sua disposição menos alternativas que os homens, já que a desigualdade de gênero, a despeito dos avanços alcançados, continua mantendo a grande maioria da população feminina em posição social de desvantagem.

Ao mesmo tempo, as alternativas oferecidas por esses sistemas de significados sexuais são, para homens e mulheres, condicionadas por suas inserções de classe, sendo em geral mais restritas para as classes populares. "As mesmas estruturas que limitam o acesso à educação, segurança econômica e mobilidade social, simultaneamente, limitam o acesso aos sistemas de significados sexuais disponíveis para os setores mais privilegiados"."

De maneira similar operariam as diferenças regionais, fazendo supor que em áreas urbanas de regiões menos modernizadas, menos industrializadas, como o Nordeste, ${ }^{\text {I2 }}$ os discursos sobre prazer e erotismo, por exemplo, que constroem os sistemas de referência sexual, têm uma parte menos significativa na estruturação das concepções sexuais, que seriam, por sua vez, predominantemente moldadas pelos condicionantes de classe e de gênero, nos quais a questão do poder é central.

Por outro lado, em um contexto distinto, onde os impactos sociais de um alto grau de urbanização são mais visíveis, como em São Paulo, por exemplo, encontramos homens e mulheres de classe média se relacionando no terreno sexual a partir da demarcaçăo das suas diferenças, enquanto o conflito resultante do inegável contexto de favorecimento do masculino não é trazido para o interior da relação. A vivência feminina das suas relações com o parceiro, e vice-versa, não se estabelece necessariamente a partir de uma tensão entre ser possuidor/ser despossuída, o que de modo algum equivale a negar essa realidade social. Em lugar disso, utilizam distintos recursos para explicar racionalmente como tais diferenças operam, apoiando-se nos discursos da ciência, da medicina e da psicologia.

Finalmente, uma última consideração com relação à categoria gênero diz respeito à sua dimensão relacional, ao focalizar não os sujeitos descontextualizados, mas as relações sexuadas que estes estabelecem entre si - as relações de gênero. Embora de difícil operacionalização, com relação à sexualidade tal perspectiva analítica reveste-se de especial importância, por ser essa uma atividade basicamente relacional. Mediante a comparação dos discursos femi-

11. R. G. Parker, Corpos, Prazeres.... op. cit., p. 250.

12. Cabc relembrar que as observaçôes sobte o impacto das diferenças regionais nos discursos $\mathrm{c}$ práticas relativos à sexualidade são ainda preliminares, na medida em que constituem dados iniciais de un estudo em andamento no Instituto de Medicina Social/JERJ. 
nino e masculino é possível, por exemplo, compreender melhor a incorporação e a interação dos significados sexuais entre homens e mulheres, visualizando assim as diferenças, semelhanças e contradiçōes que compöem o universo relacional no qual acontecem as negociações sexuais.

Nesse sentido, por exemplo, a diferença entre "vontade" e "necessidade", que orienta respectivamente as percepções da sexualidade da mulher e do homem e, conseqüentemente, o encontro sexual entre mulheres e homens, determina o lugar que esse encontro ocupa na relação do casal e as pautas de negociação na esfera da sexualidade, cujos limites ultrapassam o espaço circunscrito temporal e físicamente das relações sexuais. ${ }^{13}$ A dependência que se instaura em torno da relação sexual por conta do binômio necessidade/vontade inverte, de certa forma, os pólos que em geral ordenam a relação. A mulher, por dispor de sua "vontade" e ter como função a promoção de um bem que o homem necessita, ganha "poder".

Fica evidente que, ao menos no âmbito do casamento, o sexo, para além de ser uma "eventual" expressăo idílica ou erótica, se configura como um importante assinalamento de que os acordos necessários à manutenção do casal estão mantidos. Mais do que uma negociação relativa ao prazer sexual, os códigos e acordos que balizam a prática do sexo no interior do casamento traduzem e asseguram um nível de negociação mais abrangente entre as partes, necessária para se desfazer ou rearrumar o gap existente entre "necessidade" e "vontade".

Tampouco o prazer sexual constitui, necessariamente, finalidade primeira e única da relação sexual, e novamente a diferença de gênero se faz marcante: de saída, a sexualidade feminina, bastante atrelada à reprodução e/ou ao amor, relativiza o prazer enquanto prioridade do encontro sexual. A mulher, presa ao sentimento, resguardada por resquícios do amor romântico, e o homem que precisa "descarregar" são figuras do imaginário social. Essa relação atrela sexo a sentimento para a mulher e descola, com facilidade, estas duas categorias no caso dos homens, justificando comportamentos e estabelecendo os limites da negociação sexual com argumentos que variam desde "uma determinação da natureza", até "conseqüências de produções culturais".

Ainda nesse campo da negociação, a AIDS em cena incentiva a disseminação da "cultura do conhecer" e da "cultura da confiança": a dissecação de histórias de vida nos planos familiar e afetivo-sexual e o envolvimento transformam, como num passe de mágica, indivíduos em sujeitos sadios e sinceros. O restrito

13. Ver discussão a esse respeito em W. V. Villela e R. M. Barbosa, Repensando as Relaçōes entre Scxualidade e Gênero, trabaiho apresentado no scminário Sexualidades Brasileiras, Rio de Janeiro, Instituto de Medicina Social/UERJ, 1994, mimeo. 
poder de barganha da mulher "acostumada" a correr riscos sem que necessariamente os tematize ou opte por eles se consolida ainda mais, reforçado pelo medo - contraface do sentimento - de perder o parceiro, pela insegurança da vida sem o outro, pela falta de informaçăo e autonomia sobre ela, e tantos outros fatores.

Assim, é possível pensar que a negociação e a adoção ou não de práticas sexuais mais seguras estão determinadas por uma equação muito mais complexa do que em geral as propostas de intervenção comportamental costumam admitir ou as soluções tecnológicas possam garantir.

Além disso, a compreensão das formas peculiares mediante as quais se processa a diferenciação masculina e feminina e a relação destas com as estruturas de poder que as mantêm, é fundamental para pensarmos um processo de negociação sexual, que se passa no interior de um universo relacional e tem por referência um contexto sócio-histórico no qual muito rapidamente vêm sendo modificados os padrões tradicionais de definição de mulher e homem.

\section{RESUMO}

\section{Entre a Vontade e a Necessidade: Negociação Sexual em Tempos de AIDS}

Ao quadro de precariedade em que se encontra a saúde no Brasil se aliam o crescimento do uso de contraceptivos, do número de mulheres chefiando famílias, do nível de escolaridade das mesmas, paralelamente ao seu empobrecimento. Nota-se, ampliando este quadro, uma progressão acelerada da epidemia de HIV/AIDS junto à população feminina, infectada, em sua maioria, por via sexual.

A inexistência, até os dias de hoje, de um método que previna a transmissão sexual do vírus e seja regulado pelas mulheres torna urgente a discussão sobre as relações desiguais de gênero, que mantêm as mulheres em situação de desvantagem, nos planos individual e social, e interferem no processo de tomada de decisões voltadas à proteção de sua saúde e de sua integridade física. Com o presente artigo pretende-se discutir a complexidade das relações entre gênero e poder que permeiam os encontros sexuais entre homens e mulheres, delimitando e modelando, entre outras coisas, as possibilidades de negociação de práticas sexuais mais seguras. 


\section{ABSTRACT \\ Between Desire and Need: \\ Sexual Negociation in Times of AIDS}

The growth of the use of contraceptive, of the number of women as head of families, and of their level of education, together with their impoverishment are combined to the poor estate in which the health in Brazil is. We noticed that, enlarging this picture, a quick advancing of HIV/AIDS epidemics among the feminine population, infected, mainly, by way of sexual transmission.

Up to now, the inexistence of a method, determined by women, to prevent the sexual transmission of the virus make urgent the discussion of the inequal relations between the genders, that kecp women in an inferior position in the social and individual levels, and interfere in the process of decision taking related to their health and physical integrity protection. With this article we intend to discuss the complexity of the relation between gender and power that permeates the sexual encounters between men and women, delimitating and shaping, among other things, the possibilities of safer sexual practices negotiation.

\section{RÉSUMÉ}

\section{Entre la Volonté et la Necessité: Négociation Sexuelle en Temps de SIDA}

Dans la situation de précarité où se trouve la santé au Brésil, s'ajoutent la croissance de l'usage de contraceptifs, du nombre de femmes chefs de familles et de leur de scolarité, parallèlement à son appauvrissement. On note, en amplifiant cette situation, une progression acceléré de l'epidemie du HIV/SIDA auprès de la population feminine, infectée, en sa majorité, par voie sexuelle.

L'inexistence, jusqu'à nos jours, d'une méthode qui previenne la transmission sexuelle du virus et qui soit reglé par les femmes, rends urgent la discussion sur les relations inégales du genre, qui maintient les femmes en situation de désavantage, dans les plans individucl et social, et interferent dans le procédé de prendre des décisions tournées vers la protection de sa santé et de son intégrité physique. Avec cet article, on pretend discuter la complexité des relations entre genre et pouvoir qui traversent les rencontres sexuelles entre les hommes et les femmes, en délimitant et modelant entr'autre, les possibilités de négociation de pratiques sexuelles plus sûres. 